\title{
DEL PECADO ORIGINAL A LA RENTA BÁSICA: SUPEREMOS DE UNA VEZ EL CASTIGO DIVINO Y GARANTICEMOS EL DERECHO A VIVIR DIGNAMENTE.
}

\section{FROM ORIGINAL SIN TO BASIC INCOME: LET US FINALLY OVERCOME DIVINE PUNISHMENT AND GUARANTEE EVERY CITIZEN TO LIVE WITH DIGNITY}

\author{
Carmen García Pérez \\ Abogada y economista, Murcia, España \\ carmengarciaperez87@gmail.com
}

Recibido: octubre de 2020

Aceptado: noviembre de 2020

\section{Palabras clave: renta básica, política social, servicios sociales, dignidad, libertad.}

Keywords: universal basic income, social policies, social services, dignity, freedom.

\begin{abstract}
Resumen: este artículo pretende mostrar la Renta Básica como una inversión en lugar de un gasto. La Renta Básica es una herramienta de carácter preventivo cuya efectividad es incalculable porque evita incurrir en múltiples situaciones que abocan a las personas en incipiente estado de necesidad a otras cuyos efectos son frecuentemente irreversibles. Desde que Adán y Eva cometieron el pecado original nuestra sociedad está vertebrada por el trabajo, a pesar de que éste ya no es garantía de una vida digna. Afrontar la pobreza con la Renta Básica no sólo la erradicaría, sino que, de paso, serviría para distribuir la riqueza en un momento en que la desigualdad en su reparto se encuentra en máximos históricos. Otorgaría a las personas la libertad que las políticas sociales de los últimos cuarenta años no otorgan y haría posible garantizar el derecho a la vida digna.
\end{abstract}

Abstract: this article aims to show Universal Basic Income as an investiment instead of an expense. Universal Basic Income is a preventive tool which effectiveness is invaluable. It avoids incurring in multiple situations that lead people in an incipient state of need to others whose effects are frequently irreversible. Since Adam and Eve committed the original sin, our society has been structured by work, even though work is no longer a guarantee of a dignified life. Tackling poverty with Basic Income would not only eradicate it, but also serve to distribute wealth at a time when inequality in its distribution is at an all-time high. It would give people the freedom that the social policies of the last forty years have not provided and would make it possible to guarantee the right to a dignified life. 
«La verdadera grandeza de esta vida consiste en llegar a ser dueño de uno mismo»

Daniel Defoe, Robinson Crusoe (1719)

\section{Del Jardín del Eden al precariado}

El paraíso de Adán y Eva que recoge el Génesis relata que éstos disfrutaban de una felicidad edénica y un bienestar que estaba al margen de la actividad laboral. La condición para poder permanecer en ese estado era no comer el fruto del árbol de la ciencia pues, si lo hacían, les permitiría conocer y juzgar el bien del mal. Como todos sabemos, esa condición fue incumplida y Adán y Eva fueron expulsados del paraíso. Podemos afirmar que los habitantes de ese paraíso disfrutaban de un "modelo débil de renta básica". ${ }^{1}$

A partir de ese momento, surgen dos propuestas y la segunda marcará significativamente nuestra estructura social:

- de una parte, quienes creen que llegará un momento en que volverán a disfrutar de esa "renta básica original"2 (Isaías); y

- de otra parte, quienes creen que sin el sudor del trabajo el ser humano no podrá redimirse del pecado ni alcanzar la felicidad (San Pablo).

Es decir, mientras que Isaías abre la puerta de la esperanza a un mundo con Renta Básica, San Pablo la cierra de golpe ${ }^{3}$. Desde entonces, nuestra sociedad es ver-

1. (Iglesias Fernández, 2004)

2. Como se cita en Iglesias Fernández (2004, pág. 9).

3. Ibidem. tebrada por el factor trabajo y esta idea cristiana permanecerá, de forma generalizada, en la moral de cristianos y no cristianos. Entre éstos últimos la variedad de pensadores es notable.

La defensa del trabajo como requisito para garantizar una vida digna es una idea compartida por ideologías muy distintas. Aún podemos leer programas políticos que afirman que "la clave es crear empleo. Es empleo, empleo y más empleo". "Es generar las condiciones para que se cree cada día más y mejor empleo". Lo anterior está extraído, literalmente, de las primeras páginas del programa con el que el Partido Popular concurrió a las elecciones de 2018 ${ }^{4}$. Se ha escogido por su claridad, pero no por su originalidad. El Partido Popular no está solo en la búsqueda del pleno empleo, le acompañan en esta anacrónica travesía las principales fuerzas políticas del país. Teóricamente en las antípodas ideológicas, Izquierda Unida proponía un plan que garantizara el derecho al trabajo digno para todas las personas. Según su programa electoral, esta actuación supondría la puesta en marcha del denominado Plan de Trabajo Garantizado 5 .

También, desde hace algunos años, son muy comunes y frecuentes las políticas de empleo autonómicas, tramitadas a

4. Esta misma propuesta se ha mantenido, aunque con otra literalidad en los programas electorales. Disponible en http://www.pp.es/sites/default/ files/documentos/programa-electoral-eleccionesgenerales-2016.pdf (consultado el 10/10/2020).

5. Esta propuesta se ha mantenido durante las últimas convocatorias electorales. Véase Programa electoral de Izquierda Unida para las elecciones generales del $10 \mathrm{~N}$ de 2019, disponible en https:// izquierdaunida.org/programa-electoral-de-izquierda-unida-para-las-elecciones-generalesdel-10n-de-2019/ (consultado el 10/10/2020). 
través de los Ayuntamientos, que consisten en otorgar subvenciones y fomentar la contratación pública basada en criterios sociales ${ }^{6}$-llevadas a cabo por parte de gobiernos de distinto signo político-. Se trata de políticas que no se evalúan y evidencian carencias a la hora de fijar con claridad qué modelo de estado de bienestar queremos. Pero no solo eso, la proliferación de este tipo de políticas nos alejan del estado de bienestar y nos acercan, aun sin saberlo muchos de quienes proponen e implementan estas ayudas, al denominado workfare ${ }^{7}$.

6. Desde el punto de vista jurídico, las llamadas medidas de fomento del empleo local subvencionado tienen un encaje complicado en el actual marco normativo. El acceso al empleo público está contemplado en nuestro ordenamiento como un derecho fundamental (art. 23 Constitución Española) de configuración legal, que se tiene que regir por lo que también expresa el art. 103 Constitución Española. Esta configuración la han realizado el Estatuto Básico de Empleo Público y las normas de función pública autonómicas, en todo aquello que no es básico. Esta normativa legal, por imperativo constitucional, establece como pilares básicos para el acceso al empleo público la igualdad, el mérito y la capacidad. Y no hay en este marco legal ninguna regulación que exija ponderar estos valores constitucionales con otros, como el derecho al trabajo, el derecho a vivir dignamente o similares, en determinadas circunstancias. Siendo esto así, cada vez que las Comunidades Autónomas aprueban programas para que las administraciones locales contraten a desempleados, pasando éstos a ser empleados públicos durante un tiempo, se están obviando los parámetros del art. 103 CE y se están primando las circunstancias personales. Más allá de la conveniencia y la justicia social de la medida, lo cierto es que el marco legal no estaba pensado para este tipo de acceso al empleo público. Sería conveniente realizar las modificaciones oportunas para dar encaje legal adecuado a las necesidades sociales y laborales actuales.

7. Cuando hablamos de workfare lo que estamos diciendo es que para poder tener acceso a deter-
Mientras nuestra sociedad mantiene el trabajo como columna vertebral, los servicios públicos y las entidades sociales atienden en gran medida a personas que tienen un empleo ${ }^{8}$. El $13.2 \%$ de los trabajadores en España son pobres y con ello queremos decir que no alcanzan los 7.700 euros anuales. Que el trabajo no garantiza una vida digna es una cuestión que ya denuncian incluso las instituciones católicas. Así, un reciente informe de la Fundación FOESSA recoge que el $52,2 \%$ de las familias con una situación de inestabilidad laboral grave no disponen de dinero para afrontar gastos imprevistos y el $42,0 \%$ se han visto en la obligación de pedir ayuda económica a parientes 0 amigos (Fundación FOESSA, 2020).

minadas prestaciones sociales es necesario trabajar. Así, este modelo característico de Estados Unidos y Reino Unido constituyó el paso de un sistema de derechos -welfare- a un sistema de obligaciones -workfare- vinculadas a esos derechos. "El trabajar se convierte en un deber y deja de ser un derecho" (Méndez de Vigo, 2013). El workfare lo conforman una serie de programas que exigen el retorno al mercado laboral para poder acceder al cobro de prestaciones sociales. En este modelo prima, claramente y a cualquier precio, la inserción laboral. Se entiende que la forma óptima de inserción social es el empleo. No obstante, las políticas de workfare pueden llegar a ser conflictivas por vulnerar los Derechos más básicos de los ciudadanos. En el año 2013 una ciudadana británica impugnó en sede judicial tener que trabajar sin remuneración alguna en la famosa cadena de supermercados "Poundland", lo que dio lugar a varias sentencias y, finalmente, la Corte de Apelación declaró que el programa "back to work", tal y como estaba configurado, contravenía la el Convenio Europeo para la defensa de los Derechos Humanos. Y es que incluso el arzobispo de York denunció públicamente la inmoralidad que para él suponen este tipo de políticas sociales.

8. (Cáritas Española, 2019) 
Los datos son contundentes al evidenciar que el empleo no es ya una medida útil para erradicar la pobreza. En la actualidad, tener un empleo no garantiza poder disfrutar de un nivel de vida digno y esto no es sólo achacable a España.

Si tenemos en cuenta la situación descrita, creemos que la Renta Básica se presenta como una medida que puede, entre otras cosas, ocupar los huecos que ha dejado libres el empleo. Es decir, en tanto que el trabajo ya no es una medida de inserción social, no garantiza una vida digna y parece que ni siquiera habrá trabajo para todos en un futuro no muy lejano ${ }^{9}$, la Renta Básica reconfiguraría el sistema de relaciones laborales de una forma beneficiosa para el conjunto de la sociedad. Ahora bien, ¿cómo sería el mercado de trabajo con la Renta Básica? Las ventajas de su implantación en lo que atañe a las relaciones laborales tienen que ver con el aumento del poder de negociación, la mejora de las condiciones laborales y el favorecimiento de la iniciativa personal.

Estos beneficios, si bien parecen obvios, se ven ensombrecidos por las reticencias culturales. El rechazo tiene una enorme carga religiosa, económica y social. En lo que atañe al ámbito religioso, no podemos olvidar la maldición divina que nos dice "te ganarás el pan con el sudor de tu frente" y San Pablo que considera que "el que no quiera trabajar que tampoco coma" ${ }^{10}$

En el plano económico, se considera que para poder participar en la renta que se produce es preciso trabajar o tener medios propios de capital. En tanto que éstos son minoría, la forma habitual de obtener los recursos es a través del trabajo. Por último, las reticencias sociales tienen que ver con la

9. (Frey \& Osborne, 2013)

10. Segunda Carta a los Tesalonicenses, capítulo III. opinión extendida de que el trabajo dignifica. En opinión de una parte de la población, el trabajo constituye un instrumento fundamental para la socialización del hombre y, de hecho, hay quienes hablan de la obligación moral de trabajar (Iglesias Fernández, 2002). Sin embargo, parece que las reticencias se extienden sólo al que carece de medios porque "a quien dispone de medios de capital no se le exige el trabajo para vivir". Realmente, la necesidad de trabajar se corresponde con una determinada forma de organizar la sociedad y distribuir la renta. Una propuesta como la Renta Básica indica que esto puede cambiar.

En definitiva, hay que superar "la falacia de que una vida sin pobreza es un privilegio por el que hemos de trabajar, en lugar de un derecho que todos merecemos" (Bregman, 2017). Sea el fin del trabajo o no, lo cierto es que éste ya no constituye un elemento de integración social ni garantiza una vida digna, como sí lo hacía antes. Tenemos que asumir que estamos ante un nuevo tiempo.

\section{El precio de la pobreza y la necesaria optimización del gasto social}

Mi experiencia en los servicios sociales de un pequeño municipio hace ya algún tiempo que me hizo reflexionar acerca del coste que la pobreza tiene para el conjunto de la sociedad. En ese servicio donde me di cuenta de las derivaciones que me llegaban y de que yo, a su vez, también derivaba a las personas a otros servicios y profesionales. Veo en este servicio cómo una misma persona, a raíz de una situación de dificultad económica comienza una carrera de obstáculos para lograr subsistir, pidiendo prestaciones asisten- 
ciales a todas las administraciones. Las consecuencias en los niños, en ellos mismos -su salud, sus decisiones, sus problemas...- y en la población en general son importantes. Una misma persona requiere multitud de recursos y todos ellos son, justamente, gratuitos.

Ante esta situación, es lógico preguntarse si no es más sencillo dar directamente una cantidad de dinero, que gestionar complejos expedientes para conseguir al final que llegue a quien lo necesita una cuantía inferior. Al final, parece que dar directamente dinero es más justo y más eficiente. Esta pregunta no he sido la primera que se la ha hecho. Milton Friedman, que actuó como asesor tanto del presidente Nixon como de Reagan, se pronunció firmemente frente a la burocracia cuando defendía la conveniencia de un pago en metálico a las personas en lugar de financiar la costosa maquinaria administrativa. Argumentaba que los programas de ayudas, con frecuencia, resultaban contraproducentes y tan sólo servían para perpetuar la pobreza en lugar de aliviarla. Acerca de la Renta Básica sostenía que el planteamiento no era tan radical, "puesto que el conjunto de medidas de asistencia y de bienestar existentes ya habían generado un ingreso anual garantizado por el Gobierno, aunque fuese sólo en sustancia, y no en nombre" (Rifkin, 2004 (original de 1994), 434)

Además, las consecuencias de las situaciones de pobreza las pagamos entre todos: medicinas, sanidad, juzgados, abogados de oficio, psicólogos, etc. Aún de forma fraccionada y condicionada, las personas en situación de necesidad económica ya tienen reconocidas muchas prestaciones. Quizá la ineficacia se encuentra, no tanto en la falta de gasto, sino en cómo se está gastando.
En esta situación, creo que el planteamiento más acertado para afrontar las situaciones de pobreza es partir de que ésta nos incumbe a todos y de que ésta la pagamos entre todos. Que haya familias cronificadas en los servicios sociales no solo afecta a los descendientes de esas familias, sino que afecta al conjunto de la sociedad que, aun sin saberlo -y quizá sin quererlo-, paga las consecuencias.

Ahora bien, es posible hablar con precisión acerca de los beneficiarios de prestaciones asistenciales ${ }^{11}$ y del coste que tienen. Sin embargo, el gasto que ocasiona la pobreza va más allá y, en este sentido, los servicios sociales municipales ${ }^{12}$ son, a

11. Y ello a pesar de la enorme maraña prestacional que rige nuestro ordenamiento jurídico. A modo de ejemplo, señalaremos que solo el desempleo no contributivo lo conforman a día de hoy: el subsidio por desempleo por tener cargas familiares; el subsidio por desempleo para mayores de 45 años sin cargas familiares; el subsidio por desempleo para mayores de 52 años; la Renta Activa de Inserción (RAI); y el subsidio extraordinario. Que lo anterior es ineficaz y complejo no es una opinión aislada de quien suscribe. Tal y como expuso el Gobierno en la exposición de motivos del Real Decreto-ley 28/2018, de 28 de diciembre, para la revalorización de las pensiones públicas y otras medidas urgentes en materia social, laboral y de empleo, es preciso un nuevo modelo. Señala que "en consecuencia, el Gobierno asume el compromiso de presentar un nuevo modelo de protección por desempleo asistencial en los cuatro primeros meses de 2019, que sustituya el hasta ahora vigente modelo complejo, disperso e ineficaz". Huelga decir que durante los primeros meses de 2019 no se produjo la tan deseable integración de prestaciones, sino que en 2020 se ha añadido una más a la normativa de la Seguridad Social: el Ingreso Mínimo Vital.

12. El acceso a los servicios sociales públicos está suficientemente extendido como para tomarlo de referencia. No obstante, no se pueden ignorar las entidades sociales que, paralelamente, también intervienen. Sobre este particular, es importante 
mi entender, el lugar donde mejor se comprende lo conveniente que resulta la Renta Básica. Las historias personales, los casos concretos y no las estadísticas son las que realmente muestran cómo la pobreza afecta a las decisiones vitales, las trampas de la pobreza, la salud, la educación, la conflictividad judicial y burocracia, por citar algunos ejemplos. fundamentalmente, desde los servicios sociales

\section{I Burocracia}

En todo caso, se actúa frente cuando la necesidad urgente e inmediata ya existe. La propia normativa que regula las prestaciones asistenciales provoca esta situación. Existen personas que acuden en busca de ayuda con carácter preventivo, cuando saben que su situación va a empeorar. Sin embargo, los requisitos de la totalidad de las prestaciones asistenciales y ayudas están condicionadas a la situación de pobreza acreditada. Es decir, la configuración que existe de las prestaciones hace que la prevención sea muy residual cuando no inexistente. Por ello, es frecuente encontrar rechazos en las primeras ocasiones en que se tramitan ayudas -porque la persona y su familia no se encuentran aún en la situación de pobreza que exige la norma-.

La burocracia es ingente y se encuentra hasta en los casos en que la situación de necesidad no se limita a cuestiones económicas. La tramitación de expedientes

tener en cuenta lo frecuente que es encontrar poblaciones en las que las entidades sociales son, realmente, unos servicios sociales paralelos y, además, financiados en parte con dinero público. Esto ocasiona ineficiencias en el sistema. Como venimos diciendo, puede que no se trate tanto de la falta de gasto -que también- sino la forma en que éste se lleva a cabo. de discapacidad e invalidez, con sus múltiples revisiones y exámenes, generan un coste asociado muy significativo. En igual sentido, la tramitación de los expedientes a nivel municipal y/o autonómico que sólo traen causa en necesidades económicas $-y$ no las que precisan intervenciones de otro tipo- hay veces que alcanzan un coste altísimo por la cantidad de escritos, comunicaciones y recursos que precisan de diferentes profesionales. La transferencia directa de esa cantidad al usuario aportaría una eficacia doble al sistema: el profesional podría dedicar esos recursos a tareas más propias de trabajo social, que no se limiten a la gestión burocrática; y el usuario obtendría más ingresos efectivos.

La burocracia no sólo es ingente sino también contradictoria. Reseñaremos a continuación dos ejemplos que, lamentablemente no son aislados, y se corresponden con situaciones reales.

El primero de ellos tiene que ver con las personas que acumulan deudas con la Seguridad Social. Es frecuente en las personas trabajadoras autónomas con empleados a su cargo. Se trata, sencillamente, de personas que en algún momento les fue mal y no afrontaron a tiempo la deuda. Esa deuda sólo crece cada día y es imposible que pueda hacer frente a ella. El problema que encontramos es cómo afecta a los trabajadores autónomos el tener deudas con la administración para poder percibir la pensión de jubilación en su modalidad contributiva. Las consecuencias son terribles tanto para el propio sistema como para la persona deudora. De conformidad con la Ley ${ }^{13}$, es preciso

13. Esta cuestión está prevista en el artículo 28 del Decreto 2530/1970, de 20 de agosto, por el que se regula el régimen especial de la Seguridad Social de los trabajadores por cuenta propia o autónomos, que regula las condiciones del derecho 
estar al corriente en el pago de las cuotas para poder acceder a las prestaciones por las que se ha cotizado. Sin embargo, en situaciones de falta de ingresos ${ }^{14}$ este requisito genera un círculo vicioso que sólo conduce a que servicios sociales termine gestionando una pensión de jubilación no contributiva. La consecuencia no es sólo injusta -no se tiene en cuenta lo que se ha cotizado, ya que Seguridad Social te priva directamente de las prestaciones por el hecho de tener deudas- sino que genera más gasto por otras vías. Esta persona acude a los servicios sociales, que le gestionarán otro tipo de prestaciones. Prestaciones con un importe económico más bajo, lo que conduce, a su vez, a la necesidad de que se gestionen varias.

El segundo de ellos se encuentra en personas mayores de 52 años ${ }^{15}$ que no pueden acceder al subsidio por desempleo para personas de su edad porque no cumplen uno de los requisitos, que consiste en haber cotizado durante noventa días a la Seguridad Social. Para solucionar este problema, desde Servicios sociales se suele buscar una entidad social que contrate a esta persona y así pueda acceder a la prestación. Lo absurdo del sistema se encuentra en que donde se acude para la contratación es, generalmente, a entidades sociales financiadas con subvenciones públicas. Es decir, lo que no se abona a través de la prestación directa al

a las prestaciones. Exige estar al corriente en el pago de las cuotas exigibles en la fecha en que se entienda causada la correspondiente prestación.

14. Lógicamente, las situaciones de impago por fraudes u otro tipo podrían encajar en esta exigencia.

15. Actualmente, la edad está fijada en 52 años, pero antes era 55 . En cualquier caso, se trata del subsidio por desempleo pensado para personas que no se reincorporarán al mercado laboral. usuario se hace a través de su contratación laboral, financiada por la propia administración pública -mucho más costoso y, por ende, más ineficiente-.

Claramente, una Renta Básica evitaría las dos situaciones que acabamos de describir.

\subsection{Decisiones vitales}

Las decisiones vitales en los casos de pobreza están determinadas por su situación de necesidad económica. No existe planificación a largo plazo porque la duración de las prestaciones y su falta de regularidad no permite saber con certeza con qué recursos contarán. La capacidad de ahorro de las personas en situación de necesidad económica es nula. Pero resulta que la capacidad de ahorro de las personas perceptoras de los subsidios actuales es, también, inexistente. La experiencia vivida en los servicios sociales hace ver cómo el terminar una ayuda, tramitar otra antes de que ésta se agote y comenzar otra diferente genera ineficiencias en el sistema ya que el problema no se ha erradicado y la situación de la familia evidencia que lo único que necesitan es dinero.

Pondremos otro ejemplo para evidenciar que una prestación incondicional es preferible a una incondicionada. Este caso tampoco es aislado. Una persona joven cuyos padres acuden a los servicios sociales comienza un curso de formación que tiene un coste al que pueden hacer frente durante unos meses. Sin embargo, pasado un tiempo lo deja por imposibilidad de pago. Una prestación condicionada no arreglaría esta situación porque la evaluación de las rentas mínimas exige comprobar si los destinatarios han empleado el dinero en lo que se consideran nece- 
sidades básicas: alimentación, vivienda y vestido, fundamentalmente. Se olvida que muchas veces esas necesidades las pueden suplir la familia o incluso amigos.

Lo que la red de apoyo no puede ofrecer normalmente es dinero de forma regular para pagar gastos de formación u otros. El coste que supondrá para la sociedad que una persona joven no haya podido hacer el curso de formación no lo podemos saber. Las decisiones erróneas a veces no sólo tienen consecuencias individuales. Una Renta Básica otorgaría a las personas la libertad de elegir qué hacer con el dinero, pero, sobre todo, eliminaría las trampas de la pobreza y permitiría tomar decisiones a largo plazo -más acertadas, seguramente- que redundarían en el conjunto de la sociedad.

Al hilo de lo anterior, se observa con mucha frecuencia en el ámbito social la derivación continua a programas formativos cuya efectividad es prácticamente inexistente. Lo cierto es que las actividades realizadas por numerosas entidades sociales, financiadas con fondos públicos, puede que no sean del interés de quienes se ven obligados a acudir. Sin embargo, quien muestra interés por una actividad concreta carece de la ayuda económica necesaria para poder llevarla a cabo. Una Renta Básica daría libertad a las personas para formarse en función de sus inquietudes o intereses y no en función de las condiciones que imponen las prestaciones asistenciales condicionadas.

\subsection{Salud}

Las situaciones de dificultad económica estresan a las personas y el empeoramiento de la salud complica la situación. Se observa en los servicios sociales una falta de tratamiento adecuado de los problemas de salud porque se dedican más recursos a cubrir las necesidades básicas. De hecho, es común el comentario entre trabajadores sociales relativo a que la gestión de ayudas asistenciales entorpece la tarea de intervención en la que habría que incidir con muchas personas. En este sentido, no es mera intuición el hecho de que un ingreso estable podría mejorar la vida de las personas.

El Mincome fue un proyecto llevado a cabo durante la segunda mitad de los años setenta en una pequeña población rural llamada Dauphin de la provincia de Manitoba (Canadá). La importancia de este experimento radica en que, por vez primera, la muestra se correspondía con la totalidad de la población, es decir, los 10.000 habitantes de Manitoba. Nadie estaba excluido y no se ha vuelto a realizar un experimento de esta naturaleza hasta la fecha.

La propuesta que se hizo a la población consistía en lo siguiente: se ofrecía a las familias sin ingresos una cantidad equivalente al $60 \%$ del $\mathrm{LICO}^{16}$ (umbral de bajos ingresos). Para saber de qué estamos hablando, a día de hoy, esa cantidad ascendería a 27.000 dólares canadienses anuales (para una familia de 4 miembros). Esta cantidad variaba dependiendo del número de miembros de la familia. El presupuesto fue de 17 millones de dólares de entonces, y se destinó a financiar la renta mínima de unas mil familias. Lamenta-

16. LICO es el acrónimo de Low income cutoff. Es la referencia que se utiliza desde el año 1959 en Canadá para saber qué familias se espera que gastarán más en necesidades básicas (alimentación, vestido y vivienda). Pueden consultarse los umbrales en https://fullskillsexamprep.com/ blog/2015-lico-low-income-cutoff/ (consultado el 10/10/2020). 
blemente, la duración del experimento fue breve y el análisis de sus resultados inexistente cuando finalizó. El Mincome empezó en 1974 y terminó en 1979 sin informe final y sin ningún tipo de estudio porque la ingente documentación que se recabó, por motivos políticos, acabó en cajas del Archivo Nacional de Canadá.

No fue hasta el año 2011 cuando la profesora Evelyn L. Forget publicó un artículo ${ }^{17}$ tremendamente interesante para comprender lo beneficioso que resulta para la sociedad implantar una renta mínima. Utilizó los datos de la sanidad pública ${ }^{18}$ para analizar qué efecto tuvo el Mincome durante los cuatro años que duró. Y lo cierto es que todos ellos son positivos, el Mincome fue un éxito.

En una población con gran autoempleo en la agricultura, el Mincome ofreció estabilidad y predictibilidad en los ingresos. Se redujeron de forma muy significativa las hospitalizaciones (un 8,5\%) y las visitas al centro de atención primaria. En muchas ocasiones, la percepción que uno mismo tiene de su salud tiene que ver con el desasosiego que provoca la falta de ingresos. El hecho de no tener ese problema, hizo que muchas personas dejaran de sentirse enfermos. En suma, se pudo concluir que la certeza en los ingresos determina en gran medida la salud de las personas.

Como siempre, por parte de un sector del ámbito público existía la preocupación de que la implantación de un ingreso mínimo desmotivara a la gente a trabajar. Sin embargo, el número total de horas trabajadas

17. (Forget, 2011)

18. El programa Medicare se implantó en 1970, con lo que los archivos médicos proporcionaron a la profesora Forget abundante información para comparar la salud y otros aspectos de los habitantes de Dauphin, con los de otros lugares. sólo se redujo un $1 \%$ ente los hombres, un 3\% entre las mujeres casadas y un $5 \%$ entre las mujeres solteras. Realmente, los datos conducen a conclusiones lógicas: las mujeres que habían sido madres recientemente utilizaron esos ingresos para tomarse más tiempo de baja por maternidad y los estudiantes prolongaron sus estudios.

En definitiva, este estudio nos sirve para introducir el concepto de poor health, que se utiliza en el artículo, y que no es más que el triste hecho de que la pobreza

\section{empeora la salud.}

Al estudio realizado por la profesora Forget, tenemos que añadir los estudios de Pickett ${ }^{19}$. En esta misma línea, vincula las desigualdades económicas y sociales al empeoramiento del estado de salud de las personas, entre otras cosas. Según ella, la ansiedad vinculada al temor de ser pobre propicia conductas compulsivas y adictivas. En el ámbito nacional, Sergi Raventós es un conocido defensor de la Renta Básica, vista ésta siempre desde el punto de vista de la salud mental ${ }^{20}$.

El pago de la Renta Básica ofrece una estabilidad emocional que evitaría las situaciones de salud precaria relacionadas con la falta de cobertura de necesidades básicas. No sólo beneficiaría a la persona sino que, a largo plazo, se ahorraría en gasto público y nos beneficiaríamos el conjunto de la sociedad.

\subsection{Justicia}

Para terminar, pondremos algunos ejemplos relacionados con la justicia. Es difícil cuantificar lo que suponen los procedi-

19. (Wilkinson \& Pickett, 2011)

20. (Raventós S. , 2020) 
mientos judiciales porque no se trata sólo de los honorarios del abogado designado de oficio (en estos casos se tiene derecho a Justicia Gratuita) sino de toda la maquinaria que implica un proceso jurisdiccional. Consideramos que todos los casos judiciales que tienen su origen en situaciones de necesidad económica desaparecían, al menos en parte, con la implantación de la Renta Básica y, con ellos, se ahorraría un gasto muy significativo. Las reclamaciones de pensiones de alimentos, determinados conflictos familiares, las reclamaciones de deuda, las ejecuciones hipotecarias, los procesos de reclamación de rentas de alquiler... son procesos judiciales que afectan de una forma especial a las personas sin recursos.

La experiencia en servicios sociales exige resaltar varias situaciones que, de existir una Renta Básica, probablemente, no tendrían lugar.

En primer lugar, la responsabilidad personal subsidiaria ${ }^{21}$. Es una medida absolutamente desconocida para quienes cuentan con ingresos. Sin embargo, es algo habitual en los entornos sin recursos el ingreso en prisión porque el condenado a pagar la multa impuesta por el Juzgado penal no ha hecho frente a ella. Esta situación ocasiona un trastorno en las

21. Está prevista en el artículo 53 del Código Penal que establece que si el condenado no satisficiere, voluntariamente o por vía de apremio, la multa impuesta, quedará sujeto a una responsabilidad personal subsidiaria de un día de privación de libertad por cada dos cuotas diarias no satisfechas, que, tratándose de delitos leves, podrá cumplirse mediante localización permanente. También podrá el juez o tribunal, previa conformidad del penado, acordar que la responsabilidad subsidiaria se cumpla mediante trabajos en beneficio de la comunidad. En este caso, cada día de privación de libertad equivaldrá a una jornada de trabajo. familias muy importante. Los equilibrios familiares se descompensan. Esta pena no es propia de las personas con recursos económicos, de suerte que la responsabilidad personal subsidiaria es una medida que afecta al colectivo más pobre de nuestra sociedad. Es posible también la realización de trabajos en beneficio de la comunidad; algo que, igualmente, afecta a la situación económica del condenado que tendrá que dejar su empleo -si lo tiene- o encontrará mayores dificultades de inserción por no contar con toda la jornada laboral.

Traemos a colación esta pena porque, en tanto que afecta a quienes no pueden pagar las multas, contraviene el principio de igualdad consagrado en nuestra Constitución. Evitan la prisión quienes tienen medios económicos para afrontarlas.

En segundo lugar, son frecuentes los procedimientos judiciales -civiles y penalespara reclamar pensiones de alimentos entre ex parejas con hijos en común. Los procesos civiles no tienen más consecuencias que la condena al pago de la cantidad debida. Sin embargo, la urgencia con la que se necesita muchas veces el dinero hace que se acuda a la jurisdicción penal para reclamar estas cantidades. La diferencia no es irrelevante. En el ámbito penal, la condena incluye multa y prisión. Para las personas en situación de pobreza, que su ex pareja opte por esta vía -al margen de apreciaciones que no vienen al caso- implica que tendrá que pagar preferentemente la multa si no quiere incurrir en la responsabilidad personal subsidiaria que se acaba de comentar. Y, en el mejor de los casos, si paga la multa, ese dinero se destina al Tesoro Público y no al pago de los alimentos. Por tanto, en situaciones de necesidad económica acudir a la vía penal añade un coste que va destinado al 
dinero público, pero no a las necesidades de los niños, que son los beneficiarios de las pensiones de alimentos.

En tercer lugar, los procedimientos de reclamación de deudas (rentas de alquiler, ejecuciones hipotecarias) abocan con frecuencia al empleo irregular. No es raro escuchar a personas que afirman preferir un empleo irregular a uno con cotizaciones a la Seguridad Social cuyo salario podría ser embargado por la administración de justicia. Las deudas, judicialmente, sólo aumentan (intereses y costas del procedimiento) y esto motiva que cantidades que podrían haber sido pagadas fraccionadamente en los inicios, resulten imposibles de pagar con el paso del tiempo. Se alcanzan cantidades muy altas que motivan que las personas prefieran vivir indefinidamente al margen de la regularidad laboral. Esto causa efectos negativos en el futuro de las personas que, cuando alcancen la edad de jubilación, no tendrán derecho a una pensión contributiva. La dependencia de prestaciones asistenciales estará siempre presente.

El pago de una Renta Básica mejoraría las situaciones descritas y ello redundaría en el conjunto de la sociedad generando un ahorro que, si bien se puede precisar, sí se puede asegurar que sería muy importante.

\section{Caminos opuestos: el ingreso mínimo vital}

El pasado 1 de junio, el Boletín Oficial del Estado publicó el Real Decreto-Ley 20/2020, por el que se establece el Ingreso Mínimo Vital (IMV). Se trata de una nueva prestación de la Seguridad Social, de carácter estatal, similar a la ya existente en los países de nuestro entorno. Hasta ahora estábamos habituados a las prestaciones de este tipo de las Comunidades Autónomas ${ }^{22}$ que, con diferentes denominaciones, otorgaban una ayuda a los hogares en situación de necesidad. A pesar de que el IMV es una prestación estatal, se prevé que su acceso sea "multicanal", siendo sin duda los Ayuntamientos uno de los canales que más personas atenderán. Inicialmente, para orientar a todas las personas interesadas en solicitarlo y, más adelante, conforme se suscriban los Convenios que prevé la norma, gestionar las solicitudes (artículo 22 RD-Ley 20/2020).

El IMV es el camino opuesto a la Renta Básica, que se define como "una renta incondicionalmente garantizada a todos de forma individual, sin necesidad de una comprobación de recursos o de estar realizando algún trabajo". ${ }^{23}$ Y se asemeja, por compartir la mayoría de sus características, a las rentas mínimas autonómicas ${ }^{24}$.

22. Puede consultarse un cuadro detallado de todas ellas en (García Pérez, 2019). "Rentas mínimas autonómicas: actualización de la monografía sobre Renta Básica. Disponible en https://www. acalsl.com/blog/2019/04/rentas-minimas-autonomicas-actualizacion-de-la-monografia-sobrerenta-basica (consultado el 01/10/2020). (García Pérez, 2019)

23. Definición del Basic Income Earth Network (BIEN) disponible en https://basicincome.org/ about-basic-income/ (consultado el 01/10/2020)

24. Al respecto, merece la pena traer a colación el sistema de renta garantizada vasco. El único con resultados evaluados por su antigüedad. Sin embargo, autores como Hernández Uribarri (Hernández Uribarri, 2015), gran conocedor de este sistema que lo sigue de cerca desde sus comienzos, lo considera un auténtico fracaso que no debiera extenderse al conjunto del país. Después de tres años en los que ya existió crecimiento económico $(2014,2015$ y 2016) los datos de pobreza se mantuvieron casi invariables a los años de crisis. Aun mejorando las cifras de empleo, lo que la EPDS evidenció es que el sistema 
Las rentas autonómicas so prestaciones asistenciales subsidiarias, condicionadas, limitadas en el tiempo, revisables y necesitadas de una alta burocracia. Para quien las percibe, todas estas rentas condicionadas constituyen la renta máxima a la que pueden aspirar mientras la perciben (un "techo"), mientras que la Renta Básica es la renta mínima con la que un individuo puede contar (un "suelo"). Las prestaciones condicionadas están orientadas a la disminución de la pobreza, pero son absolutamente ajenas a la distribución de la riqueza. Y, como ocurre con estas rentas de nivel autonómico, el IMV se caracteriza por:

- no ser universal, ya que podrán ser beneficiarios quienes se encuentren en el rango de edad de 23 a 65 años;

- no ser individual, al estar dirigido a los hogares y, además, hogares que habrían de estar constituidos al menos 1 año antes de la solicitud (artículo 6 RDLey 20/2020);

- fijar una renta máxima (llamada renta garantizada) a la que se pueda aspirar, en lugar de ser el "suelo" desde el que todo ciudadano parte;

- actuar ante situaciones de pobreza ya establecidas (requisito de encontrarse en situación de especial vulnerabilidad, según el artículo 8 RD-Ley 20/2020); y

- condicionar la conducta de las personas, al prever expresamente que hay que ser demandante de empleo y la elaboración de itinerarios de inclusión

RGI sigue dejando fuera al $30,7 \%$ de personas en riesgo de pobreza. Y de esas personas pobres que no acceden a las prestaciones, más del 50\% tienen un empleo (lógicamente, muy precario). También se comprueba que las personas que acceden a la prestación, sólo el 3,3\% consigue superar la pobreza (Gobierno Vasco, 2017). en cooperación con las comunidades autónomas y entidades locales.

Por lo que respecta a la cuantía, ésta varía en función de los miembros de la unidad de convivencia. Así, por ejemplo, asciende a 461,5 euros mensuales para un adulto; y asciende a 839,93 euros mensuales para una familia de dos adultos y dos menores de edad.

Como vemos, el IMV es el camino opuesto a la Renta Básica; no se trata de un paso previo a ella, como algunos han Ilegado a afirmar. Se trata de conceptos diferentes que, como tales, se basan en modelos distintos. El IMV, además, ha motivado la modificación de las normativas autonómicas relativas a las rentas mínimas, que han de ajustarse a la existencia de esta nueva prestación estatal.

La realidad del IMV en los Servicios Sociales -al menos en los que quien suscribe conoce en primer persona- es que numerosas personas que consideran ser potenciales beneficiarios se han encontrado con resoluciones administrativas estereotipadas, carentes de contenido, que se pronuncian sobre su solicitud sin ningún tipo de fundamento que pueda sustentar la decisión adoptada. La plantilla utilizada por el Instituto Nacional de la Seguridad Social para denegar el IMV solamente señala "supera ingresos", dejando a quien no tiene ingresos completamente perplejo y, por supuesto, indefenso ante tal argumentación. Es la definición de acto administrativo nulo por falta de motivación ${ }^{25}$.

También existe otra plantilla, en la que solamente se concreta el importe mensual a percibir por el beneficiario del IMV, pero si

25. Pero para conocer de cerca la historia de un expediente administrativo en el ámbito social, merece la pena leer Silencio administrativo de Mesa (2019) 
ninguna referencia de cálculo que, para quien esperaba otra cuantía, pudiera servir para entender lo que percibe. Es decir, nos encontramos ante uno de los mayores defectos que presentan estas ayudas: la incertidumbre. La incertidumbre que ocasionan a quienes la han de percibir, que provoca vivir sin poder planificar, ahorrar, y termina abocando a decisiones desafortunadas o, directamente, impide salir de la trampa de la pobreza.

$Y$, en fin, no hay viñeta que defina mejor el sistema de prestaciones asistenciales condicionadas que la que se muestra a continuación de El Roto.

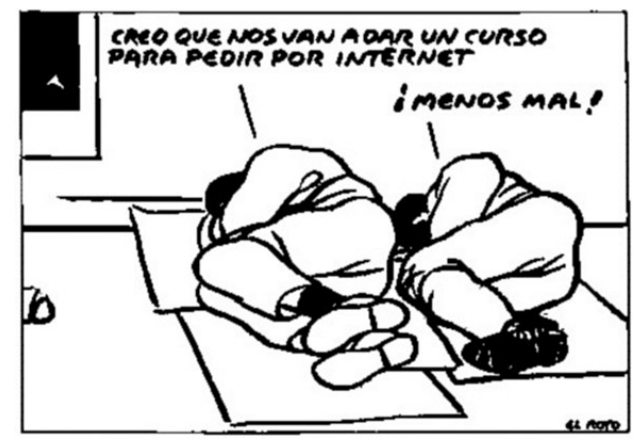

El Roto (publicado en El País). Tomado de http:// letrasdenada.blogspot.com/2013/10/examen-ylicencia-de-mendigo.html

\section{Libertad y dignidad}

"Toda persona, como miembro de la sociedad, tiene derecho a la Seguridad Social, y a obtener mediante el esfuerzo nacional y la cooperación internacional, habida cuenta de la organización y los recursos de cada Estado la satisfacción de los derechos económicos, sociales y culturales, indispensables a su dignidad y al libre desarrollo de su personalidad". ${ }^{26}$ Lo anterior es el artículo 22 de la Declaración Universal de los Derechos Humanos que, como puede apreciarse, no entiende una

26. El subrayado es propio. vida digna y libre sin la satisfacción de determinados derechos.

La vida digna tiene que ver con el acceso a un determinado bienestar que, irremediablemente, pasa por alimentación, vestido, vivienda, cultura... Así, el artículo 25 de la Declaración establece el derecho de todas las personas a un nivel de vida adecuado que le asegure, así como a su familia, la salud y el bienestar $\mathrm{y}$, en especial, la vivienda. En similares términos, el Pacto Internacional sobre Derechos Económicos, Sociales y Culturales, reconoce en su artículo 11.1 "el derecho de toda persona a un nivel de vida adecuado para sí y su familia, incluso alimentación, vestido y vivienda adecuados, y a una mejora continua de las condiciones de existencia". ${ }^{27}$ Siendo esto así, el propio artículo recoge la obligación de los estados para hacer efectivo este derecho al establecer expresamente que Los Estados Partes tomarán medidas apropiadas para asegurar la efectividad de este derecho. Garantizar a los ciudadanos un ingreso mínimo trae causa en la dignidad y la libertad de las personas; en la oportunidad real de hacer lo que valoramos; en el autoestima, como bien primario y como sentimiento del propio valor (Raventós, 2007, 48).

Si nos situamos en el plano europeo y acudimos a la Carta de los Derechos Fundamentales de la Unión Europea ${ }^{28}$

27. El subrayado es propio.

28. El 1 de diciembre de 2009, la Carta pasó a ser jurídicamente vinculante. Ahora, según el artículo 6, apartado 1, del Tratado de la Unión Europea "la Unión reconoce los derechos, libertades y principios enunciados en la Carta de los Derechos Fundamentales de la Unión Europea [...], la cual tendrá el mismo valor jurídico que los Tratado". Por consiguiente, la Carta forma parte del Derecho primario de la Unión y, como 
encontramos los valores sobre los que está en coherencia con ello, el articulado de la CE inicia con la declaración de España como un "Estado social y democrático de Derecho, que propugna como valores superiores de su ordenamiento jurídico la libertad, la justicia, la igualdad y el pluralismo político" (art. 1.1.). Asimismo, dentro de los principios rectores que han de regir las políticas españolas, tenemos importantes referencias que traemos a colación. El apartado primero del artículo 39 establece la obligación de los poderes públicos de asegurar la protección social, económica y jurídica de la familia. Inmediatamente después, los arts. 40.1 y 41 nos dicen lo siguiente con relación a las rentas de los ciudadanos y las prestaciones sociales suficientes para atender situaciones de necesidad:

«Los poderes públicos promoverán las condiciones favorables para el progreso social y económico y para una distribución de la renta regional y personal más equitativa (...)» (artículo 40.1)

«Los poderes públicos mantendrán un régimen público de Seguridad Social para todos los ciudadanos que garantice la asistencia y prestaciones sociales suficientes ante situaciones de necesidad, especialmente en caso de desempleo» [artículo 41]

Parece perfectamente encuadrable en nuestra Constitución la implantación de una renta a todas las personas porque, al fin y al cabo, se trata de una redistribución de la renta en los términos que ésta misma exige.

tal, sirve de parámetro de referencia a la hora de examinar la validez del Derecho derivado y de las medidas nacionales. Recuperado en http:// www.europarl.europa.eu/atyourservice/es/displayFtu.html?ftuId=FTU_1.1.6.html (consultado el 01/10/2020).
Dicho lo anterior, entendemos que no hay que atacar sólo la pobreza cuando se acredita que se es pobre, ex post, sino que hay que poner en marcha instrumentos de futuro a través de la actuación ex ante.

Los sistemas de prestaciones asistenciales condicionales tiene una importante incidencia en la libertad y la dignidad de las personas, así como las situaciones de pobreza, que impiden que los ciudadanos puedan participar plenamente en la sociedad. Estas ideas están expresamente recogidas en la Exposición de motivos del recién aprobado Ingreso Mínimo Vital que, lamentablemente, no logra esa participación plena que pretende.

Acudir a los servicios sociales para recibir determinada asistencia -nos referimos a la solicitud de ayudas para necesidades básicas- es para muchísimas personas un acto casi de humillación, en el que tienes que detallar con frecuencia aspectos íntimos y justificar "cómo he llegado hasta aquí". Así, se pronuncia Hernández Uribarri cuando habla de la RGI vasca:

“¿Por qué la puerta de entrada al sistema son las trabajadoras sociales que someten a la gente solicitante a entrevistas humillantes, en la mayoría de casos y no un procedimiento documental similar al del desempleo o al de las pensiones de la Seguridad Social?" (Hernández Uribarri, 2012, 79)

Bregman (2017), al referirse a la burocracia y hablar de la inutilidad que ésta supone, señala lo siguiente:

"Mientras de los empleados se espera que demuestren sus capacidades, los servicios sociales exigen a los solicitantes que demuestren sus limitaciones; que justifiquen una y otra vez, y sin lugar a dudas, que su enfermedad los debilita, que su depresión 
los incapacita y que su probabilidad de conseguir empleo es escasa. De lo contrario, pierden su subsidio. Formularios, entrevistas, controles, recursos, evoluciones, consultas y luego aún más formularios, cada proceso de solicitud de asistencia tiene su propio protocolo degradante que devora dinero" (Bregman, 2017, 93).

Una Renta Básica mejora la libertad de las personas y su dignidad, al mejorar las condiciones de vida. Al ser incondicional, la Renta Básica no es una limitación de acceso al mercado de trabajo. Previsiblemente, muchas personas entenderán que el importe de la Renta Básica no es adecuado para el nivel de vida y consumo al que aspiran. La Renta Básica otorga más libertad. Además, la pobreza es un indicador de erróneas decisiones vitales, conflictos familiares, enfermedades ligadas a la frustración y el estrés, inseguridad alimentaria, educación deficiente y problemas con la justicia (Segal, 2016). La forma en que podrían mejorar las condiciones de vida es inestimable.

En definitiva, hay que romper el vínculo del empleo como único medio de acceso a una remuneración para poder vivir dignamente. Hay que desterrar la idea de la Renta Básica como gasto y verla como una inversión, que es su verdadera naturaleza.

\section{Bibliografía}

Bregman, R. (2017). Utopía para realistas. A favor de la renta básica universal, la semana laboral de 15 horas y un mundo sin fronteras (Primera ed.). Barcelona: Ediciones Salamandra.

Cáritas Española. (2019). Economía y Personas. Trabajar por lo que es justo. Obtenido de https://bit.ly/3jypLFg
Forget, E. L. (2011). The town with no poverty. Using Health Administration Data to Revisit Outcomes of a Canadian Guaranteed Annual Income Field Experiment. Canadian Public Policy, 37(3), 283-305. Frey, C. B., \& Osborne, M. A. (2013). The Future of Employment: How Susceptible are Jobs to Computerisation? Technological Forecasting and Social Change, 114, 254-280.

Fundación FOESSA. (2020). Vulneración de Derechos. Trabajo decente. Obtenido de https://bit.ly/3iyhQ9K

García Pérez, C. (10 de abril de 2019). Blog de ACAL. Obtenido de Rentas mínimas autonómicas: actualización de la monografía sobre Renta Básica

Gobierno Vasco. (2017). Encuesta de Pobreza y Desigualdades Sociales. Departamento de empleo y políticas sociales. Obtenido de http://www.euskadi.eus/ gobierno-vasco/-/informacion/encuestade-pobreza-y-desigualdades-socialesepds/

Hernández Uribarri, I. (2012). Historia y futuro de las rentas mínimas en Euskadi. Cuadernos de Trabajo Social, 25-1, 7585. Obtenido de http://revistas.ucm.es/ index.php/CUTS/article/view/38435

Hernández Uribarri, I. (2015). No es una buena idea extender el sistema de rentas mínimas condicionadas de Euskadi al conjunto del Reino de España. SinPermiso. Obtenido de https://www.sinpermiso. info/textos/no-es-una-buena-idea-extender-el-sistema-de-rentas-minimas-condicionadas-de-euskadi-al-conjunto-del

Iglesias Fernández, J. (2002). La Renda Bàsica a Catalunya. (F. J. Bofill, Ed.) Barcelona: Mediterrània.

Iglesias Fernández, J. (2004). La cultura de las rentas básicas (historia de un concepto). Barcelona: Virus editorial. Obtenido de http://rentabasica.net/Autores00.pdf 
Mesa, S. (2019). Silencio administrativo. La pobreza en el laberinto burocrático. Barcelona: Anagrama.

Raventós, D. (2007). Las condiciones materiales de la libertad. Barcelona: Intervención cultural.

Raventós, S. (23 de mayo de 2020). Se acerca una epidemia en salud mental y tal vez podríamos evitarla. El Salto Diario. Obtenido de https://www.elsaltodiario. com/renta-basica/se-acerca-epidemiaen-salud-mental-y-tal-vez-podriamosevitarla

Rifkin, J. (2004 (original de 1994)). El fin del trabajo. Nuevas tecnologías contra puestos de trabajo: el nacimiento de una nueva era. Barcelona: Paidós.

Segal, H. (2016). Finding a Better Way: A Basic Income Pilot Project for Ontario. Massey College in the University of Toronto, Toronto. Obtenido de https://www. ontario.ca/page/finding-better-way-basicincome-pilot-project-ontario

Wilkinson, R., \& Pickett, K. (17 de septiembre de 2011). The Spirit Level: Why Equality is Better for Everyone. Penguin Press. Obtenido de http://www. ara.cat/suplements/diumenge/gentconscient-desigualtats-seves-consequencies_0_1871212867.html 